\title{
Book review: Undisciplining knowledge: Interdisciplinarity in the twentieth century \\ Graff, H.J. (2015), JHU Press
}

Magdalena Karolak

Zayed University, UAE

Undisciplining knowledge: Interdisciplinarity in the twentieth century by Harvey Graff systematically traces back the formation, organization and delimitation of scientific disciplines. The point of departure is interdisciplinarity, defined as questions, problems and means to answer them in novel ways rather than as a simple aggregation of many disciplines into one. Given the recent rise of interdisciplinarity, which seems to be becoming a dominant form of scholarly work, the author seeks to grasp its meaning while confronting the existing dichotomies, myths and conflicts that surround the notion of interdisciplinarity. The aim of this exercise is to understand the potential and the limits stemming from organizing a field of knowledge in a particular way. In order to reorient our understanding of interdisciplinarity, the account goes back to the time when "there were neither disciplines nor interdisciplines" and Graff follows the prominent figures of the field, institutional arrangements and the political and social contexts to unveil the complex processes of construction of particular disciplines. The book is organized chronologically and the author presents comparative case studies of genetic biology and sociology, humanities and communication, social relations and operations research, cognitive science and new histories, materials science and cultural studies, bioscience and literacy studies. The reconstruction of these historical processes is meticulous and takes the readers to the core of debates surrounding the formation of each of the disciplines, whether successful or not.

Ultimately, Graff offers his assessment of the reshaping of disciplines over time. These comparative examples are often striking. Biology, for instance, formed as a convergence of multiple disciplines. It had a greater appeal to position itself as the science of life, hence had a firmer ground to assert its place as a science, as opposed to sociology, which struggled to position itself as the science of society. Sociology, as Graff explains, failed to be an integrative science of society since, unlike biology, it narrowed down its interdisciplinary scope. It emerged in the process of differentiation from other social sciences rather than from interdisciplinary collaboration and integration. Attempts to remedy this drawback were undertaken later on with the idea of establishing social relations as a new scholarly discipline. Despite the efforts undertaken at Harvard University at creating this new interdisciplinary social science, the idea did not take root due to institutional establishment flaws. Although a department of social relations under the leadership of Talcott Parsons was created and initially generated a lot of interest, lack of integration of the interdisciplinary parts led to its intellectual disintegration and ultimately, dissolution of the department. In contrast, operations research, which shared some developmental commonalities with social relations, proved to be a success. Graff explains that unlike social relations, operations research provided scientific methodologies, practical questions, and systematic inquiry that were more focused and specific. In addition, promotion of the new discipline in wider circles, academic and nonacademic, was more successful in grounding it firmly as a separate discipline. The book continues relating further histories of successful and failed interdisciplines. In the last chapter, the author reaches recent developments in the field of interdisciplinarity in academia, opening questions over the future shapes, successful or not, it may take. The book ends, however, with warnings over the misuse of the 
label of interdisciplinarity, highlighting "the dangers of exaggeration, excessive claims of novelty, and imitation, especially of a simplified model of scientific research".

The book is a very well researched and well written account of the history of interdisciplinarity and the history of the formation of scientific disciplines. The readers will find it an extremely informative account that presents key discussions over the emergence and reshaping of new scientific disciplines, creation of academic curricula, specifically general education and core courses curricula, and development of modern humanities, among others. It is a must-read for any academic who wishes to gain a holistic overview of the patterns of creation, shaping and organization of knowledge at modern universities. Working in a department of interdisciplinary studies, and coming from an interdisciplinary academic background myself, the book immediately caught my attention. I found it very insightful professionally, since apart from explaining the complex processes of contruction of modern disciplines, it also helped me reposition some of the concerns and debates surrounding interdiciplinarity. Graff adds an important voice in the discussions over interdisciplinarity and his definition of the term is helpful in making interdisciplinarity a meaningful one. The concerns are not unfounded as interdisciplinarity is often equated with lack of sound scientific basis, oversimplification and overgeneralization of research problems, methods and solutions. This is unfortunately the legacy of overspecialization and fragmentation of modern scientific disciplines that interdisciplinary disciplines and programs ought to remedy. In the process, some interdisciplines were more or less successful as the book shows. However, the bias against interdisciplinarity as a "no discipline" persists. It is also due in part to the misuse of the label, which has been applied to everything outside the established disciplines.

The author justifiably warns that "talking" interdisciplinary differs from doing it in practice. Going back in history to the beginning of patterns of organization is helpful in highlighting the creation of the currently well-established disciplines that have, as it is shown, interdisciplinary backgrounds. Furthermore, the reading will no doubt be beneficial to academic administrators who oversee the organization of university units and the creation of curricula. The analysis of failures of interdisciplinary academic disciplines and departments are insightful. What, however, is missing from the book is a concluding chapter that would summarize the work, providing clearer and more general insights into what recommendations the author could offer based on the case studies presented in the book. The book ends with half-page conclusion of the last chapter leaving the reader looking for more. As it is the case with the case studies that form the book, the reader is left wondering how these experiences of failure and success could be generalized into patterns and applicable criteria for assessment. In addition, given the multiple debates presented, a conclusion would be beneficial to clearly delineate what constitutes a discipline, a multidiscipline, an interdiscipline, and a professional field. Is it that, once well established, an interdiscipline may be ultimately considered a discipline? However, this drawback does not undermine the work, which will no doubt remain the major work in the field of interdisciplinarity in the years to come. And since the interdisciplinary projects are on the rise, as the book asserts, research of this kind is more than ever needed. 